\title{
Synthesis and Photophysical Characterization of Proton Transfer-Based Thiourea Derivatives: Potential Application as Colorimetric Naked-Eye Chemosensor for Fluoride Detection in Solution
}

\author{
Cláudia B. da Silva, Thais Kroetz, Fabiano S. Santos and Fabiano S. Rodembusch* \\ Grupo de Pesquisa em Fotoquímica Orgânica Aplicada, Instituto de Química, \\ Universidade Federal do Rio Grande do Sul (UFRGS), Av. Bento Gonçalves, 9500, \\ 91501-970 Porto Alegre-RS, Brazil
}

\begin{abstract}
Two new thiourea derivatives were synthesized through the reaction of photoactive aminohydroxybenzazoles and $p$-isothiocyanate benzoic acid via nucleophilic addition reaction. The compounds were characterized using high resolution mass spectrometry with eletrospray ionization (HRMS-ESI), Fourier transform infrared (FTIR), ${ }^{13} \mathrm{C}$ and ${ }^{1} \mathrm{H}$ nuclear magnetic resonance (NMR) spectroscopies. UV-Vis and steady-state fluorescence in solution were also applied to characterize their photophysical behavior. The compounds present absorption in the ultraviolet region (ca. $300 \mathrm{~nm}$ ) and fluorescence emission with a large Stokes' shift in the UV-A and green region, with the longer wavelength related to phototautomerism in the excited state (ESIPT). Both compounds were investigated as optical sensors for the detection of anions in solution, presenting a potential application for fluoride ion detection by naked-eye and UV-Vis spectroscopy. The continuous variation method plot gave a 1:1 stoichiometric ratio between the chemosensors and $\mathrm{F}^{-}$for the new formed species. The UV-Vis and ${ }^{1} \mathrm{H}$ NMR titration experiments reflect the establishment of a hydrogen bond interaction between the thiourea moiety of the chemosensors and fluoride. In addition, the presence of fluoride in solution tailored the fluorescence emission of one compound favoring the ESIPT emission.
\end{abstract}

Keywords: ESIPT, optical sensors, benzazoles, fluoride ion, fluorescence

\section{Introduction}

Anion detection using luminescent and colorimetric methods has become an area of major research in recent years. ${ }^{1,2}$ In this context, the detection of the fluoride anion $\left(\mathrm{F}^{-}\right)$is of particular interest as it plays an essential role in biology, as well as in chemical applications such as water supply, or even in chemical and nuclear warfare agents. ${ }^{3-8}$ The fluoride anion is also of great interest because of its importance in the clinical treatment of osteoporosis. However, it is also harmful to the environment, sometimes playing a role in environmental pollution ${ }^{9}$ and diseases affecting human health due to its accumulation in the bones. ${ }^{10,11}$ Fluoride is also present in toothpaste in the form of sodium fluoride to prevent cavities, but its overuse can create fluorosis, resulting in bleaching or a brownish discoloration of the teeth. ${ }^{12,13}$

*e-mail: fabiano.rodembusch@ufrgs.br
In designing chemosensors with sensitive to the fluoride anion, its chemical features should be taken into account, in particular its small size and high electronegativity; these make it possible to envisage chemosensors allowing strong hydrogen bonding (HB) to the fluoride anion. ${ }^{14}$ This specific interaction has become one of those most used to signal fluoride in solution due to the availability of HB donors and its strong and selective connections with anions. ${ }^{14-17}$ In addition, the signaling unit responsible for this interaction must be responsible for the detection of the analyte using the usual spectroscopic techniques, such as UV-Vis absorption or fluorescence emission, or even naked-eye detection, the latter presenting advantages over spectroscopic techniques. ${ }^{14-17}$ According to this particular chemical interaction, different chemosensors involving urea or thiourea groups, ${ }^{18-20}$ amides, ${ }^{7}$ porphyrin ${ }^{15}$ and phenols ${ }^{6,16,17,21}$ have been described in the literature.

It is well-known that anionic chemosensors are generally composed of two parts: (i) the receiving unit, 
which is responsible for coordinating with anions through electrostatic interaction or via HB; (ii) the signaling unit, which is responsible for the detection and/or identification of the species. In this regard, compounds presenting excited state intramolecular proton transfer (ESIPT) are of interest as ESIPT phototautomerism generates a tautomeric form with a different electronic structure from the initial ground state conformer. ${ }^{22}$ Any change in the media during the ESIPT process can be useful as a photophysical response for optical sensing. The ESIPT process can generally be found in benzazoles, flavonols and chromones and can be understood as a four-level photochemical cycle that produces a tautomer with a different electronic structure from the ground state enol conformer (Figure 1). ${ }^{23}$

Numerous applications can be found in chemistry, biology and biochemistry based on these ESIPT features. ${ }^{24-30}$ The ESIPT process is characterized by a dual fluorescence emission tailored by the solvent polarity, ${ }^{31}$ with the emission from the tautomeric form ( $\left.\mathrm{T}^{*}\right)$ showing a large Stokes' shift (even in the solid state) compared to normal forms $\left(\mathrm{N}^{*}\right) .^{32}$ This particular aspect of photophysics can present potential applications in the optical sensor field, as it drastically reduces the inner filter effect, improving the fluorescence analysis. ${ }^{25}$ ESIPT compounds can be classified as photoacids, as after absorption (usually in the UV region), a donor group (generally $\mathrm{OH}$ or $\mathrm{NH}_{2}$ from a phenol or aniline group, respectively) is significantly more acid. In addition, an acceptor group present in these compounds (generally imino/azonitrogen- or carbonyl-oxygen-moieties) is also more basic, and enhances proton transfer. ${ }^{33,34}$ It is well-known that for hydroxyphenyl benzazole-based compounds in apolar or aprotic media, an enol conformer with strong intramolecular HB (IHB) between the phenolic hydrogen and the azolic nitrogen is the most stable species in the ground state. This conformer will undergo ESIPT in the excited state to produce a keto tautomer $\left(\mathrm{T}^{*}\right)$, which induces the decay in fluorescence emission to a ground state keto tautomer (T). A retro proton transfer takes place and the initial enol form is regenerated without any photochemical change (Figure 1). However, depending on the chemical structure of the fluorophore, the ESIPT mechanism can be strongly dependent on the solvent, as different conformers can be stabilized in solution in the ground state, that do not proton transfer in the excited state and decay emitting at lower wavelengths ( $\mathrm{N}^{*}$ emission) ${ }^{23}$

Thus, we present here the synthesis and photophysical characterization of two new compounds containing a fluorophoric unit, allowing proton transfer in the excited state (ESIPT) to explore phototautomerism as an additional tool for recognizing anions in solution.

\section{Experimental}

\section{Materials and methods}

All reagents and solvents were purchased from commercial suppliers and used without further purification. The solvents were dried and distilled based on procedures detailed in the literature before use. ${ }^{35}$ Spectroscopic grade solvents were used for fluorescence and UV-Vis measurements. The reactions were monitored by thin layer chromatography (TLC) carried out on Merck silica gel (60 F254). The column chromatographic purification of the products was performed on silica gel (230-400 mesh) (Aldrich). Melting points were measured with Gehaka PF 1000 apparatus and were uncorrected. Fourier transform

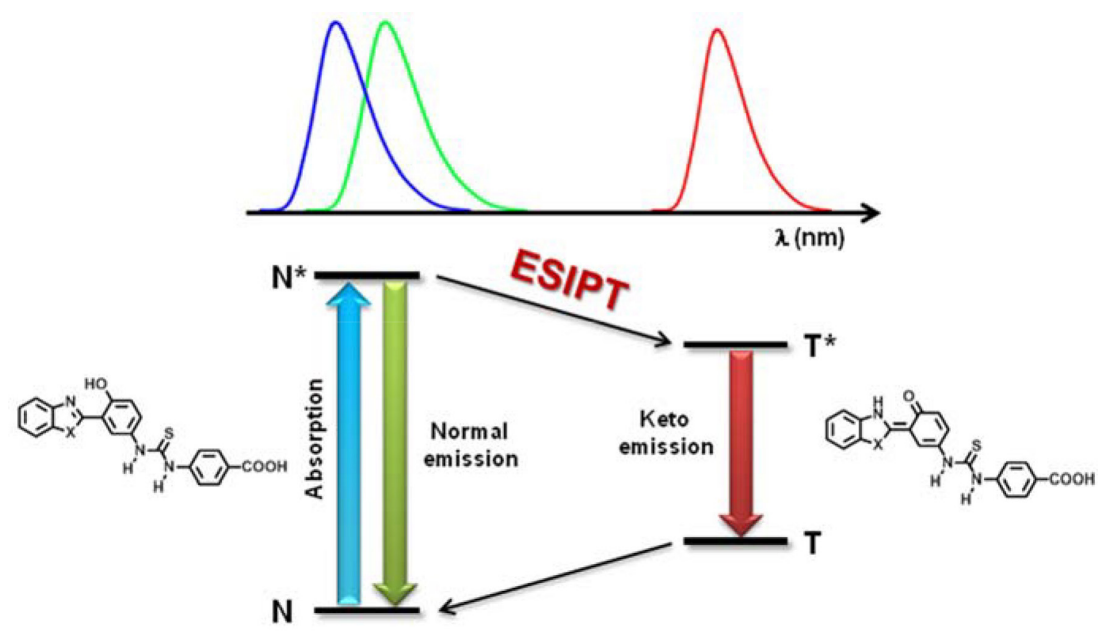

Figure 1. Four-level model for the ESIPT process for thiourea benzazole derivatives presented in this work, where $\mathrm{X}=\mathrm{O}$ or $\mathrm{S}$. The $\mathrm{N}$ and $\mathrm{T}$ indicate the normal (enol) and tautomeric (keto) forms, respectively. The asterisk designates the excited state. After $\mathrm{T}^{*}$ deactivation by fluorescence emission (keto emission) these compounds present ground state retro proton transfer. 
infrared spectroscopy (FTIR) spectra were recorded on a Mattson Galaxy series FTIR 3000 model 3020 (KBr disc). ${ }^{1} \mathrm{H}$ and ${ }^{13} \mathrm{C}$ nuclear magnetic resonance (NMR) spectra (APT, attached proton test) were recorded on a Varian Inova $300 \mathrm{MHz}$ spectrometer or Varian VNMRs $300 \mathrm{MHz}$ spectrometer. The chemical shifts were expressed as $\delta(\mathrm{ppm})$ relative to tetramethylsilane (TMS) as the internal standard and using dimethyl sulfoxide (DMSO- $d_{6}$ ) as the solvent at room temperature. Data for ${ }^{1} \mathrm{H}$ NMR were reported as follows: multiplicity ( $\mathrm{s}=$ singlet, $\mathrm{d}=$ doublet, $\mathrm{t}=$ triplet, $\mathrm{m}=$ multiplet), integration, coupling constant $(\mathrm{Hz})$ and assignment. UV-Vis absorption spectra were performed on a Shimadzu UV-2450 spectrophotometer. A slit width of 2.0 was applied in the UV-Vis measurements. Steady state fluorescence spectra were measured with a Shimadzu spectrofluorometer model RF-5301PC, using emission and excitation monochromator slit widths of 3.0/5.0. In all photophysical experiments, the absorption maximum was used as the excitation wavelength for fluorescence measurements. All experiments were performed at $25^{\circ} \mathrm{C}$ in a concentration of $10^{-5} \mathrm{~mol} \mathrm{~L}^{-1}$. High resolution mass spectrometry was recorded with electrospray ionization (HRMS-ESI) data in the positive mode using a Q-TOF-MS Bruker Impact II.

\section{Synthesis of $p$-isothiocyanate benzoic acid (2)}

A mixture of $p$-aminobenzoic acid (1) (4.0 g, $29.16 \mathrm{mmol})$ in dry acetone $(30 \mathrm{~mL})$ was added dropwise to a solution of thiophosgene $(2.24 \mathrm{~mL}, 29.16 \mathrm{mmol})$ in dry acetone $(30 \mathrm{~mL})$ at $0{ }^{\circ} \mathrm{C}$ under vigorous stirring. The reaction mixture was stirred for $3 \mathrm{~h}$. The precipitate was filtered, washed with cold acetone and dried at room temperature giving the compound $\mathbf{2}$.

\section{p-Isothiocyanate benzoic acid (2) ${ }^{36}$}

Yield: $4.2 \mathrm{~g}(87 \%) ; \mathrm{mp}>310^{\circ} \mathrm{C}$; FTIR $(\mathrm{KBr}) \vee / \mathrm{cm}^{-1}$ $3000\left(\mathrm{vC}-\mathrm{H}_{\text {arom }}\right), 2125(\mathrm{vN}=\mathrm{C}=\mathrm{S}) ;{ }^{1} \mathrm{H}$ NMR $(300 \mathrm{MHz}$, DMSO- $\left.d_{6}\right) \delta 9.96(\mathrm{~d}, 2 \mathrm{H}, J 9 \mathrm{~Hz}), 7.49(\mathrm{~d}, 2 \mathrm{H}, J 9 \mathrm{~Hz})$; ${ }^{13} \mathrm{C}$ NMR (75.5 MHz, DMSO- $d_{6}$ ) $\delta$ 166.2, 135.6, 134.1, $130.9,129.8,126.1$.

\section{Synthesis of aminobenzazoles 6-7}

In a general way, the precursors were obtained by reaction of an equimolar amount of 5-aminosalicylic acid (3) (4.0 g, $26.12 \mathrm{mmol})$ and 2-aminophenol (4) $(2.8 \mathrm{~g}, 26.12 \mathrm{mmol})$ or 2-aminothiophenol (5) $(2.76 \mathrm{~mL}$, $26.12 \mathrm{mmol})$ in polyphosphoric acid (PPA) $(60 \mathrm{~mL})$ at $170{ }^{\circ} \mathrm{C}$ for $5 \mathrm{~h}$. The reaction was followed by TLC using dichloromethane as the eluent. The reaction mixture was poured onto crushed ice and neutralized with $\mathrm{NaHCO}_{3}$ (20\%). The precipitate was filtered and dried at $60{ }^{\circ} \mathrm{C}$. The obtained compounds were purified by column chromatography eluted with dichloromethane.

2-(5'-Amino-2'-hydroxyphenyl)benzoxazol (6) ${ }^{37}$

Yield: $2.35 \mathrm{~g}(52 \%)$; $\mathrm{mp} 173-175^{\circ} \mathrm{C}$; FTIR $(\mathrm{KBr})$ $v / \mathrm{cm}^{-1} 3405\left(v_{\text {as }} \mathrm{NH}_{2}\right), 3250\left(v_{\mathrm{s}} \mathrm{NH}_{2}\right), 1630$ and 1548 $(v \mathrm{C}=\mathrm{C}) ;{ }^{1} \mathrm{H}$ NMR $\left(300 \mathrm{MHz}, \mathrm{DMSO}-d_{6}\right) \delta 10.42(\mathrm{~s}, 1 \mathrm{H}$, $\mathrm{OH}), 7.81\left(\mathrm{~m}, 2 \mathrm{H}, \mathrm{H}_{1}\right.$ and $\left.\mathrm{H}_{4}\right), 7.44\left(\mathrm{~m}, 2 \mathrm{H}, \mathrm{H}_{2}\right.$ and $\left.\mathrm{H}_{3}\right)$, $7.26\left(\mathrm{~d}, 1 \mathrm{H}, \mathrm{H}_{\mathrm{X}}, J 2.3 \mathrm{~Hz}\right), 6.84\left(\mathrm{~m}, 2 \mathrm{H}, \mathrm{H}_{\mathrm{A}}\right.$ and $\left.\mathrm{H}_{\mathrm{B}}\right), 4.96$ (s, $\left.2 \mathrm{H}, \mathrm{NH}_{2}\right) ;{ }^{13} \mathrm{C}$ NMR $\left(75.5 \mathrm{MHz}\right.$, DMSO- $\left.d_{6}\right) \delta 162.8$, 149.3, 148.6, 141.7, 139.6, 125.6, 125.2, 121.3, 119.0, 117.6, 110.9, 110.4, 109.6.

\section{2-(5'-Amino-2'-hydroxyphenyl)benzothiazol (7) ${ }^{38}$}

Yield: $1.53 \mathrm{~g}(53 \%)$; $\mathrm{mp} 196-198{ }^{\circ} \mathrm{C}$; FTIR (KBr) $v / \mathrm{cm}^{-1} 3497\left(\mathrm{v}_{\mathrm{as}} \mathrm{NH}_{2}\right), 3325\left(\mathrm{v}_{\mathrm{s}} \mathrm{NH}_{2}\right), 3000\left(\mathrm{v}_{\text {arom }} \mathrm{C}-\mathrm{H}\right)$, 1620 and $1470\left(\mathrm{vC}=\mathrm{C}_{\text {arom }}\right) ;{ }^{1} \mathrm{H}$ NMR $\left(300 \mathrm{MHz}, \mathrm{DMSO}-d_{6}\right)$ $\delta 10.72(\mathrm{~s}, 1 \mathrm{H}, \mathrm{OH}), 8.12-7.40\left(\mathrm{~m}, 4 \mathrm{H}, \mathrm{H}_{1}, \mathrm{H}_{2}, \mathrm{H}_{3}, \mathrm{H}_{4}\right)$, 7.37-7.36 (d, $\left.1 \mathrm{H}, \mathrm{H}, J_{m} 2.7 \mathrm{~Hz}\right), 6.85-6.83(\mathrm{~d}, 1 \mathrm{H}, \mathrm{H}$, $\left.J_{o} 8.7 \mathrm{~Hz}\right), 6.77-6.76$ and 6.74-6.73 (2d, $2 \mathrm{H}, \mathrm{H}, J_{m} 2.7 \mathrm{~Hz}$ and $\left.J_{o} 8.78 \mathrm{~Hz}\right), 4.8\left(\mathrm{~s}, 2 \mathrm{H}, \mathrm{NH}_{2}\right) ;{ }^{13} \mathrm{C} \mathrm{NMR}(75.5 \mathrm{MHz}$, DMSO- $\left.d_{6}\right) \delta 166.3,151.6,147.8,141.5,134.0,126.4$, 125.0, 121.9, 121.8, 119.9, 117.8, 117.6, 112.0.

General synthesis procedure for the preparation of thiourea derivatives 8-9

Compound 2 ( $0.200 \mathrm{~g}, 1.1 \mathrm{mmol}$ or $0.100 \mathrm{~g}, 0.56 \mathrm{mmol})$ in $\mathrm{CH}_{3} \mathrm{CN}(15 \mathrm{~mL})$ was added dropwise to a solution of $\mathbf{6}$ $(0.252 \mathrm{~g}, 1.1 \mathrm{mmol})$ or $7(0.135 \mathrm{~g}, 0.56 \mathrm{mmol})$ in $\mathrm{CH}_{3} \mathrm{CN}$ $(15 \mathrm{~mL})$, respectively. The mixture was stirred for $6 \mathrm{~h}$ at $70^{\circ} \mathrm{C}$. The precipitate was filtered and dried at ambient temperature. The obtained compounds were purified by column chromatography eluted with acetone:MeOH (80:20 v/v).

\section{4-(3-(3-(Benzoxazol-2-yl)-4-hydroxyphenyl)thiourea) benzoic acid (8)}

Yield: $170 \mathrm{mg}(56 \%) ; \mathrm{mp}>310^{\circ} \mathrm{C}$; FTIR $(\mathrm{KBr}) \mathrm{v} / \mathrm{cm}^{-1}$ $3480(\mathrm{vOH}), 3410-3217(\mathrm{vNH}) 3086-3029\left(\mathrm{v}_{\text {arom }} \mathrm{C}-\mathrm{H}\right)$, $1688(\mathrm{vC}=\mathrm{O}), 1605\left(\mathrm{v}_{\text {arom }} \mathrm{C}=\mathrm{C}\right) ;{ }^{1} \mathrm{H}$ NMR $(300 \mathrm{MHz}$, DMSO- $\left.d_{6}\right) \delta 11.14$ (s, $\left.1 \mathrm{H}, \mathrm{OH}\right), 10.27$ (s, 1H, NH), 10.13 $(\mathrm{s}, 1 \mathrm{H}, \mathrm{NH}), 8.16(\mathrm{~d}, 1 \mathrm{H}, J 2.7 \mathrm{~Hz}), 7.93(\mathrm{~d}, 2 \mathrm{H}, J 9 \mathrm{~Hz})$, $7.87(\mathrm{~m}, 2 \mathrm{H}, J 9.0 \mathrm{~Hz}), 7.71(\mathrm{~d}, 2 \mathrm{H}, J 9.0 \mathrm{~Hz}), 7.60(\mathrm{~d}$, $1 \mathrm{H}, J 2.7 \mathrm{~Hz}), 7.57$ (d, 1H, J 2.7 Hz), $7.48(\mathrm{~m}, 2 \mathrm{H}), 7.15$ $(\mathrm{d}, 1 \mathrm{H}, J 8.7 \mathrm{~Hz}) ;{ }^{13} \mathrm{C}$ NMR (APT) $\left(75.5 \mathrm{MHz}, \mathrm{DMSO}-d_{6}\right)$ $\delta$ 179.7, 167.7, 162.0, 154.9, 148.8, 143.6, 139.5, 131.7, 130.7, 129.8, 125.9, 125.4, 123.1, 121.7, 119.0, 117.1, 110.9, 109.8; HRMS (ESI-qTOF) $\mathrm{m} / z$ [M $+\mathrm{H}]^{+}$calcd. for $\mathrm{C}_{21} \mathrm{H}_{16} \mathrm{~N}_{3} \mathrm{O}_{4} \mathrm{~S} 406.0861$; found 406.0856 . 
4-(3-(3-(Benzothiazol-2-yl)-4-hydroxyphenyl)thiourea) benzoic acid (9)

Yield: $86 \mathrm{mg}$ (49\%); mp 240-245 ${ }^{\circ} \mathrm{C}$; FTIR (KBr) $\mathrm{v} / \mathrm{cm}^{-1} 3462(\mathrm{vOH}), 3217-3180(\mathrm{vNH}), 3100-3029$ $\left(\mathrm{v}_{\text {arom }} \mathrm{C}-\mathrm{H}\right), 1684(\mathrm{vC}=\mathrm{O}), 1605\left(\mathrm{v}_{\text {arom }} \mathrm{C}=\mathrm{C}\right), 1050-1200$ $(v \mathrm{C}=\mathrm{S}) ;{ }^{1} \mathrm{H}$ NMR $\left(300 \mathrm{MHz}, \mathrm{DMSO}-d_{6}\right) \delta 12.72(\mathrm{~s}, 1 \mathrm{H}$, $\mathrm{OH}), 11.55$ (s, 1H, OH), 10.18 (s, 1H, NH), 10.08 (s, 1H, $\mathrm{NH}), 8.28$ (d, 1H, J 2.7 Hz), 8.16 (dd, 1H, J 8.1 Hz), 8.07 (d, 1H, J $7.5 \mathrm{~Hz}), 7.92$ (d, 2H, J $8.7 \mathrm{~Hz}), 7.70(\mathrm{~d}, 2 \mathrm{H}$, $J 8.7 \mathrm{~Hz}), 7.57(\mathrm{~m}, 3 \mathrm{H}), 7.10(\mathrm{~d}, 1 \mathrm{H}, J 9.0 \mathrm{~Hz}) ;{ }^{13} \mathrm{C} \mathrm{NMR}$ (APT) (75.5 MHz, DMSO- $d_{6}$ ) $\delta 168.1,154.0,152.1$, 133.7, 128.7, 126.2, 124.2, 121.8, 121.9, 120.1, 113.6; HRMS (ESI-qTOF) $m / z$ [ $\mathrm{M}+\mathrm{H}]^{+}$calcd. for $\mathrm{C}_{21} \mathrm{H}_{16} \mathrm{~N}_{3} \mathrm{O}_{3} \mathrm{~S}_{2}$ 422.0633; found 422.0628 .

\section{Complexation studies}

The naked-eye study of compounds 8-9 was performed using tetrabutylammonium salts of the anions $\mathrm{F}^{-}, \mathrm{Cl}^{-}, \mathrm{Br}$, $\mathrm{I}^{-}, \mathrm{HSO}_{4}^{-}, \mathrm{NO}_{3}{ }^{-}$and $\mathrm{ClO}_{4}^{-}$, adding 30 equiv. of the anions in DMSO (ca. $3 \times 10^{-3} \mathrm{~mol} \mathrm{~L}^{-1}$ ) to DMSO solutions of the compounds 8-9 $\left(10^{-6} \mathrm{~mol} \mathrm{~L}^{-1}\right)$. From the obtained results in the colorimetric experiment, the UV-Vis and fluorescence emission titrations of compounds 8-9 were performed using a tetrabutylammonium salt of fluoride. To evaluate the sensitivity of these chemosensors, the concentration range was 0.1-10 equiv. of the anions in DMSO (ca. $3 \times 10^{-3} \mathrm{~mol} \mathrm{~L}^{-1}$ ). Different amounts of these solutions were added to DMSO solutions of the compounds 8-9 $\left(10^{-6} \mathrm{~mol} \mathrm{~L}{ }^{-1}\right){ }^{20}$ The continuous variation method (Job plot) was obtained from a molar fraction of 0.1-1.0 of chemosensor/fluoride. The absorbance intensity was monitored at 410 and $432 \mathrm{~nm}$ for compounds 8 and $\mathbf{9}$, respectively. ${ }^{20} \mathrm{UV}$-Vis absorption and fluorescence emission spectra were also obtained for compounds 8 and 9 after the addition of different amounts of potassium hydroxide $\left(\mathrm{KOH}, 3.57 \times 10^{-3} \mathrm{~mol} \mathrm{~L}^{-1}\right)$. In all titration experiments, after the addition of analyte, the mixture was gently stirred for $2 \mathrm{~min}$ and then the UV-Vis and fluorescence emission spectra were obtained at $25^{\circ} \mathrm{C}$. The ${ }^{1} \mathrm{H}$ NMR interaction studies were performed using the fluoride anion in DMSO- $d_{6}\left(9.54 \times 10^{-3} \mathrm{~mol} \mathrm{~L}^{-1}\right)$ at room temperature, adding different amounts of the anion solution (0.2-0.8 equiv.) to the DMSO- $d_{6}$ solution $\left(10^{-5} \mathrm{~mol} \mathrm{~L}^{-1}\right)$ of the compounds 8-9.

\section{Results and Discussion}

Synthesis

The synthesis of $p$-isothiocyanate benzoic acid (2) was performed as presented in Scheme $1 .^{36}$ It starts with a nucleophilic attack of the nitrogen atom of the amino group present in compound $\mathbf{1}$ on the electrophilic carbon from thiophosgene, and the release of chloride to form a protonated intermediate, which upon deprotonation and additional release of chloride formed compound $\mathbf{2 1}$. This reaction was performed under stirring in dry acetone at $0{ }^{\circ} \mathrm{C}$ for $3 \mathrm{~h}$ and monitored using Fourier transform infrared spectroscopy (FTIR) technique, in which it was possible to observe the disappearance of the symmetrical and asymmetric stretching bands referring to the amino group, and the appearance of an intense band of between 2000 and $2250 \mathrm{~cm}^{-1}$ relative to the isothiocyanate (-NCS) stretching (see Supplementary Information (SI) section).<smiles>Nc1ccc(C(=O)O)cc1</smiles>

(1)

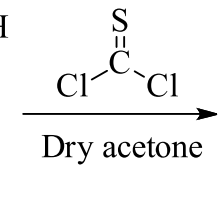<smiles>O=C(O)c1ccc(N=S)cc1</smiles>

(2)
Scheme 1. Synthetic route for obtaining $p$-isothiocyanate benzoic acid (2).

The aminobenzazole precursors 6-7 were synthesized according to the literature, ${ }^{37,38}$ in a condensation reaction of an equimolar amount of 5-aminosalicylic acid (3) with respective ortho-substituted aromatic amines 4-5 in polyphosphoric acid (PPA) (Scheme 2). Compounds 8 and $\mathbf{9}$ were obtained starting with a nucleophilic attack of the nitrogen atom of the amino group present in precursors 6 or 7 to the electrophilic carbon of $\mathbf{2}$ to produce a protonated tetrahedral intermediate, which after proton transfer formed the final products 8-9 in only one step with good yields. It should be noted that the reaction of isothiocyanates with aromatic amines is very fast, and there is no need for the use of catalysts. ${ }^{20}$ In the ${ }^{1} \mathrm{H}$ NMR spectrum of compound $\mathbf{8}$ (see SI section), it is possible to observe a singlet in the region above $11.00 \mathrm{ppm}$ relative to the hydrogen of the phenolic $\mathrm{OH}$. This signal usually appears between 4.00 and 7.50 ppm, but when IHB occurs, a frequency shift is observed for the region between 12.00 and $11.00 \mathrm{ppm} .{ }^{39}$ The disappearance of the broad signal located between 3.00 and 5.00 ppm can also be observed due to the hydrogens of the amino group of the precursor and the appearance of the hydrogens of the thiourea group in the region above 10.00 ppm. Similar results are observed for compound 9.

\section{Photophysical characterization}

The normalized UV-Vis absorption and fluorescence emission spectra of the thiourea derivatives 8-9 are 
<smiles>Nc1ccc(O)c(C(=O)O)c1</smiles>

(3)<smiles>[X]c1ccccc1N</smiles>

(4) $\mathrm{X}=\mathrm{OH}$

(5) $\mathrm{X}=\mathrm{SH}$

\section{$\underset{\text { (ii) ice, } \mathrm{NaHCO}_{3}}{\stackrel{\text { (i) } \mathrm{PPA} / 170{ }^{\circ} \mathrm{C} / 5 \mathrm{~h}}{\longrightarrow}}$}

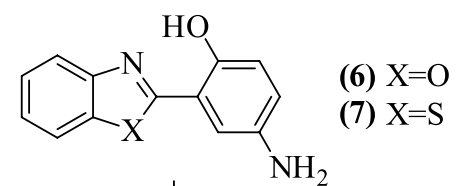<smiles>CC#N</smiles>
$\mathrm{CH}_{3} \mathrm{CN}$ $70^{\circ} \mathrm{C} / 6 \mathrm{~h}$ (2)

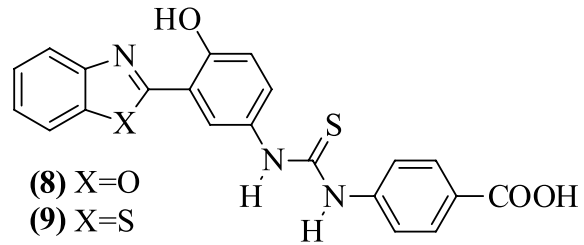

Scheme 2. Synthetic route for obtaining aminobenzazole precursors 6-7 and respective thiourea derivatives (8-9).

presented in Figure 2 and the relevant data from the photophysical study are summarized in Table 1. From UV-Vis absorption spectroscopy, it is possible to obtain the calculated radiative rate constants $\mathrm{k}_{\mathrm{e}}^{0}$ and the oscillator strengths of the electronic transitions $\left(f_{e}\right)$, applying the Strickler-Berg relations as presented in equations 1 and $2: 40$

$\mathrm{f}_{\mathrm{e}} \approx 4.3 \times 10^{-9} \int \varepsilon \mathrm{d} \bar{v}$

$\mathrm{k}_{\mathrm{e}}^{0} \approx 2.88 \times 10^{-9} \bar{v}_{0}^{2} \int \varepsilon \mathrm{d} \bar{v}$

where the integral corresponds to the area under the UV-Vis absorption curve from the plot of the molar absorptivity coefficient $\varepsilon\left(\mathrm{L} \mathrm{mol}^{-1} \mathrm{~cm}^{-1}\right)$ against wavenumber $\bar{v}\left(\mathrm{~cm}^{-1}\right)$ corresponding to a single electron oscillator. In equation 2 , $\bar{v}_{0}$ is the absorption maxima $\left(\mathrm{cm}^{-1}\right)$. In this equation, the pure radiative lifetime $\tau^{0}$ can be obtained as $1 / \mathrm{k}_{\mathrm{e}}^{0}{ }^{41}$

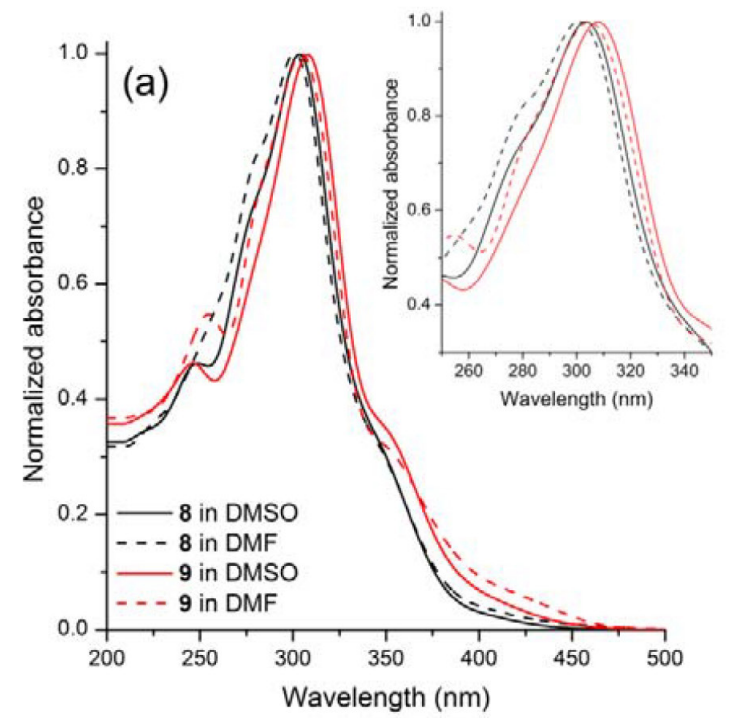

It can be observed that the compounds present absorption maxima located around $300 \mathrm{~nm}$ in dimethylsulfoxide and dimethylformamide with the molar absorptivity coefficient ( $\varepsilon$ ca. $10^{4} \mathrm{~L} \mathrm{~mol}^{-1} \mathrm{~cm}^{-1}$ ) and calculated radiative rate constants $\left(\mathrm{k}_{\mathrm{e}}^{0}\right.$ ca. $\left.10^{8} \mathrm{~s}^{-1}\right)$ indicating spin and symmetryallowed electronic transitions ascribed to ${ }^{1} \pi \pi^{*}$ electronic transitions. A similar and almost constant radiative lifetime ( $\tau^{0}$ ca. $1 \mathrm{~ns}$ ) indicates that after UV absorption, these compounds populate the same excited state. The benzothiazole derivative 9 presents an absorption maximum redshifted compared to the parent compound $\mathbf{8}$, as already observed in similar compounds, being explained by the better electron delocalization allowed by the sulfur atom compared to the oxygen atom. ${ }^{31}$ In addition, a small solvatochromic effect was observed in both compounds, with redshifted absorptions in the more polar solvent DMSO than dimethylformamide (DMF).

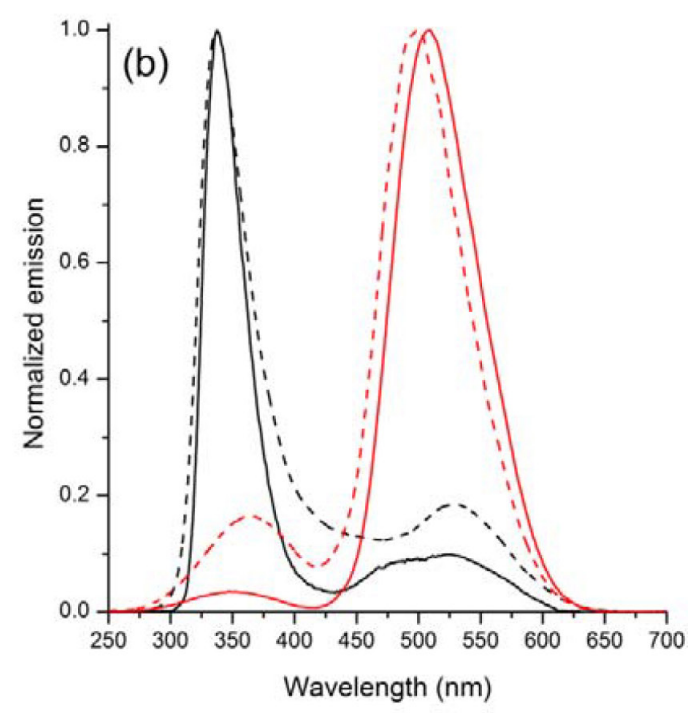

Figure 2. Normalized (a) UV-Vis and (b) fluorescence emission spectra (em./exc. slits 3.0/5.0) of $\mathbf{8}$ and $\mathbf{9}$ in dimethylsulfoxide and dimethylformamide (ca. $10^{-5} \mathrm{~mol} \mathrm{~L}^{-1}$ ). The inset presents a magnification of the absorption maxima. 
In both compounds, a dual fluorescence emission can be observed. Compound $\mathbf{8}$ presents a major emission band located around $338 \mathrm{~nm}$, with a calculated Stokes' shift $\left(\Delta \lambda_{\mathrm{ST}}\right)$ ca. $3400 \mathrm{~cm}^{-1}$ and a red-shifted one located higher than $520 \mathrm{~nm}\left(\Delta \lambda_{\mathrm{ST}}\right.$ ca. $\left.14000 \mathrm{~cm}^{-1}\right)$. Based on this result, the emission at shorter wavelengths, so-called normal emission $\left(\mathrm{N}^{*}\right)$, can be attributed to a radiative deactivation of a locally excited conformer, structurally not able to proton transfer. ${ }^{23}$ On the other hand, the emission at longer wavelengths can be ascribed to the ESIPT process, which arises from an enol-cis conformer that can present proton transfer in the excited state. ${ }^{23}$ In this process, an excited enol-cis conformer $\left(\mathrm{N}^{*}\right)$ arises, and tautomerizes to an excited-state keto $\left(\mathrm{T}^{*}\right)$ species (as presented in Figure 1). The latter decays to the ground state $(\mathrm{T})$ emitting fluorescence ( $\mathrm{T}^{*}$ emission) with a large Stokes' shift. The same result was observed for the benzothiazole derivative; however, in this compound, the main emission band is the ESIPT band $\left(\lambda_{\text {em }}\right.$ ca. $500 \mathrm{~nm}$, $\Delta \lambda_{\mathrm{ST}}$ ca. $13000 \mathrm{~cm}^{-1}$ ) rather than the blueshifted band (normal emission, $\lambda_{\text {em }}$ ca. $350 \mathrm{~nm}, \Delta \lambda_{\mathrm{ST}}$ ca. $4700 \mathrm{~cm}^{-1}$ ). These photophysical results indicate that the solvents play a different role in the stabilization of the conformers in the ground state, where compound $\mathbf{8}$ conformers not able to ESIPT are more stabilized in solution than the conformers of compound 9. Moreover, despite the similar excited state photophysics, in which a dual fluorescent was observed, the studied compounds present quite different locations on the emission maxima. The benzothiazole derivative 9 presents a normal emission, redshifted compared to the oxygen analogue 8 (14 nm in DMSO and $26 \mathrm{~nm}$ in DMF). This emission at longer wavelengths can probably be related to the better electron delocalization allowed by the sulfur atom compared to the oxygen atom in the excited state. Similar behavior was observed in parent compounds. ${ }^{31}$ In addition, as far as we know, these are the longer Stokes' shifts presented in the literature for a benzazolic compound in solution.

\section{Complexation study}

The ability of compounds 8-9 to act as anionic chemosensors was first investigated by naked-eye detection, monitoring changes in the solution color upon the addition of different anions using tetrabutylammonium salts of the anions $\mathrm{F}^{-}, \mathrm{Cl}^{-}, \mathrm{Br}^{-}, \mathrm{I}^{-}, \mathrm{HSO}_{4}^{-}, \mathrm{NO}_{3}^{-}$and $\mathrm{ClO}_{4}^{-}$in dimethylsulfoxide (DMSO). In the presence of $\mathrm{Cl}^{-}, \mathrm{Br}^{-}, \mathrm{I}^{-}$, $\mathrm{HSO}_{4}^{-}, \mathrm{NO}_{3}{ }^{-}$and $\mathrm{ClO}_{4}^{-}$, no change in color was observed in the solutions containing compounds 8-9. On the other hand, the addition of fluoride ion showed a dramatic color change in both compounds (Figure 3), probably due to $\mathrm{H}$-bonding between the receptor and $\mathrm{F}^{-}$, which increased the charge transfer in the compounds. ${ }^{6}$

The interaction with the fluoride ion was also investigated by monitoring the UV-Vis spectral changes of the thiourea derivative solutions $\left(10^{-6} \mathrm{~mol} \mathrm{~L}^{-1}\right.$ in DMSO) (Figure 4), adding different amounts of the fluoride ion (0.1-1.0 equiv.) in DMSO to the previously prepared solution of compounds 8-9. It can be observed that the compounds studied behave differently. In the absence of the fluoride ion, both compounds present an absorption band located around $300 \mathrm{~nm}$, as already discussed. However, compound $\mathbf{9}$ presents significant spectral changes upon the addition of $\mathrm{F}^{-}$. Although the original absorption band at $300 \mathrm{~nm}$ does not present relevant changes in its location and intensity, a new absorption band can be observed located around $430 \mathrm{~nm}$, being related to the binding complex between compound 9 and $\mathrm{F}^{-}$. On the other hand, compound $\mathbf{9}$ seems to be less sensitive to the fluoride ion at the studied ion concentrations. It is worth mentioning that similar behavior was observed in both compounds at a titration range of 1.4-10 equivalent of fluoride (see SI section). The difference observed between chemosensors can probably be related to the electronic character of the benzazolic unit. Due to the higher electronegativity of the oxygen atom compared to the sulfur atom, the benzazole core will present a more intense electron withdrawing effect, making the thiourea hydrogens more acidic than those present in the thiazole derivatives. It is worth mentioning that additional experiments indicate that the ability of fluoride anion to interact with the chemosensors 8-9 was not affected by the presence of chloride, bromide and nitrate anions (SI section).

It is well-known that compounds showing proton transfer in the excited state (ESIPT) can present dual

Table 1. Relevant photophysical data of compounds 8-9, in which $\lambda_{\mathrm{abs}}$ is the absorption maxima, $\varepsilon$ the molar absorptivity, $\mathrm{f}_{\mathrm{e}}$ the calculated oscillator strength, $\mathrm{k}_{\mathrm{e}}^{0}$ the calculated radiative rate constant, $\tau^{0}$ the calculated pure radiative lifetime, $\lambda_{\mathrm{em}}$ the emission maxima and $\Delta \lambda_{\mathrm{ST}}$ the Stokes' shift. The notation $\mathrm{N}^{*}$ and $\mathrm{T}^{*}$ are the normal and tautomeric emissions, respectively

\begin{tabular}{|c|c|c|c|c|c|c|c|c|c|c|}
\hline \multirow{2}{*}{ Compound } & \multirow{2}{*}{ Solvent } & \multirow{2}{*}{$\lambda_{\mathrm{abs}} / \mathrm{nm}$} & \multirow{2}{*}{$\begin{array}{c}\varepsilon / \\
10^{4}\left(\mathrm{~L} \mathrm{~mol}^{-1} \mathrm{~cm}^{-1}\right)\end{array}$} & \multirow{2}{*}{$f_{e}$} & \multirow{2}{*}{$\begin{array}{c}\mathrm{k}_{\mathrm{e}}^{0} / \\
10^{8} \mathrm{~s}^{-1}\end{array}$} & \multirow{2}{*}{$\tau^{0} / \mathrm{ns}$} & \multicolumn{2}{|c|}{$\lambda_{\mathrm{em}} / \mathrm{nm}$} & \multicolumn{2}{|c|}{$\Delta \lambda_{\mathrm{ST}} / \mathrm{cm}^{-1}$} \\
\hline & & & & & & & $\mathrm{N}^{*}$ & $\mathrm{~T}^{*}$ & $\mathrm{~N}^{*}$ & $\mathrm{~T}^{*}$ \\
\hline \multirow[t]{2}{*}{8} & DMSO & 303 & 4.7 & 0.90 & 9.83 & 1.02 & 338 & 524 & 3418 & 13919 \\
\hline & DMF & 302 & 3.9 & 0.95 & 1.04 & 0.96 & 337 & 529 & 3439 & 14209 \\
\hline \multirow[t]{2}{*}{9} & DMSO & 304 & 5.0 & 0.96 & 10.4 & 0.96 & 352 & 509 & 4486 & 13248 \\
\hline & DMF & 308 & 3.2 & 0.81 & 8.55 & 1.17 & 363 & 498 & 4919 & 12387 \\
\hline
\end{tabular}






Figure 3. Colorimetric response upon addition of 30 equiv. of tetrabutylammonium salts into DMSO solutions of compounds 8 (top) and 9 (bottom).

fluorescence emission tailored by the environment. ${ }^{23}$ As the synthesized compounds $\mathbf{8 - 9}$ present a fluorophoric unit able to proton transfer in the excited state, it was decided to investigate their fluorescence emission in the presence of different amounts of fluoride ion (Figure 5).

As already discussed, both compounds present a dual fluorescence emission. For compound $\mathbf{8}$, the major emission can be related to a normal emission $\left(\mathrm{N}^{*}\right)$ located in the UV region. On the other hand, compound 9 presents the main emission band in the green region, ascribed to the ESIPT process. From these characteristics, it is possible to affirm that compound $\mathbf{8}$ can be largely found in the ground state as non-ESIPT conformers. ${ }^{31}$ After the addition of fluoride, there is a decrease in the normal emission intensity, being related to a lower stabilization of these conformers in the presence of fluoride. In contrast, an increase in the intensity of the ESIPT emission is observed, indicating that the enol-cis conformer, responsible for the proton transfer in the excited state, is more stabilized in these conditions. This behavior indicates that the interaction of fluoride with $\mathbf{8}$ does not occur in the phenolic hydroxyl, as it would suppress the ESIPT emission. The interaction between analyte and chemosensor occurs in the thiourea portion by HB. This interaction makes the phenolic hydrogen more acidic, favoring IHB in the ground state. Regarding compound $\mathbf{9}$, the major emission based on the ESIPT process indicates the predominance of the enol-cis conformer in the ground state. In a manner not yet understood, the presence of fluoride weakly weakens the stabilization of this conformer in solution. Furthermore, for compound $\mathbf{9}$, maintenance of the ESIPT emission also indicates that the interaction mechanism does not occur with the phenolic hydroxyl.

Regarding the chemical structure of the studied chemosensors, the presence of three different acidic sites, with different $\mathrm{pK}_{\mathrm{a}}$ values, can be observed as follows: (i) carboxylic $\left(\mathrm{pK}_{\mathrm{a}}\right.$ ca. 5), ${ }^{42}\left(\right.$ ii) thiourea $\left(\mathrm{pK}_{\mathrm{a}} \mathrm{ca} .21\right)^{43}$ and phenolic $\mathrm{OH}$ with strong IHB $\left(\mathrm{pK}_{\mathrm{a}}\right.$ ca. 10$),{ }^{44}$ which will lead to different responses during the titrations with the anions. To evaluate the interaction mechanism, UV-Vis and fluorescence emission titrations were performed in different amounts of $\mathrm{KOH}$ as presented in Figure 6.

In general, it can be observed that the UV-Vis spectra, as well as the fluorescence emission of compounds $\mathbf{8}$ and $\mathbf{9}$ in the presence of $\mathrm{KOH}$, are quite different from those obtained in the same amount of fluoride ion (30-90 equiv.). Changes to the shape, maxima location, full width at half maximum (FWHM) and intensities were observed in both experiments for both compounds. In the UV-Vis titration, it can be observed that the chemosensors in the presence of $\mathrm{KOH}$ present redshifted bands. It has been reported that hydroxide generates phenolates in benzazolic-based compounds, which will present absorption bands located at longer wavelengths compared to the neutral species. ${ }^{45-47}$ It is worth mentioning that these new bands are different from those obtained in fluoride titration. The latter are due to the complex formation with the analyte.

As chemosensors are believed to exist as phenolates after titration with $\mathrm{KOH}$, these ionized species are not able to proton-transfer in the excited state. In this way, the observed broad and low intensity emission bands are due to normal emission or charge transfer emission bands. At higher amounts of fluoride, similar behavior is observed, 



Figure 4. Absorption spectra of compounds 8 (a) and $\mathbf{9}$ (b) with TBA salt of fluoride (0.1-1.0 equiv.) in DMSO. Inset: magnification between 350-500 nm of compound $\mathbf{8}$ after fluoride ion addition. The black line correspond to the pure compounds in each UV-Vis titration experiment. The continuous variation method of the complexes formed by $\mathbf{8}(\mathrm{c})$ or $\mathbf{9}(\mathrm{d})$ and $\mathrm{F}^{-}$is also presented.

in this situation, the emission at a shorter wavelength is suppressed and the emission located at longer wavelengths is the main emission band. Based on the ${ }^{1} \mathrm{H}$ NMR data, discussed in this work, the redshifted emission in the presence of fluoride can be ascribed to ESIPT emission from the chemosensor. This result indicates that the ESIPT mechanism is not affected by the fluoride.

To gain a better understanding of the binding mechanism present between the compounds 8-9 and the fluoride ion, ${ }^{1} \mathrm{H}$ NMR titration was performed in DMSO- $d_{6}$ at room temperature and the spectral changes produced by the addition of $\mathrm{F}^{-}$were analyzed. Figure 7 presents the partial spectra (9-12 ppm) of the compounds 8-9 upon the addition of different amounts of the fluoride ion. The full spectra can be found in the SI section.
Compound $\mathbf{8}$ before the addition of fluoride presents ${ }^{1} \mathrm{H}$ NMR signals from thiourea $\mathrm{NH}$ located at 10.13 and $10.27 \mathrm{ppm}$ (asterisk). In general, after the addition of different amounts of fluoride, the NH signals seem to lose resolution and collapse with the hydroxyl hydrogen to a broad signal after the addition of 0.8 equiv. of $\mathrm{F}^{-}$. The addition of 0.2 equiv., besides bringing the signals, shifts both signals downfield around $0.5 \mathrm{ppm}$ (10.64 and $10.77 \mathrm{ppm}$ ). After the addition of 0.4 equiv. of fluoride, the signals collapse to a single broad signal located between 10.74 and $10.98 \mathrm{ppm}$, becoming closer to the hydroxyl hydrogen located at $11.13 \mathrm{ppm}$. In the presence of 0.6 equiv. of fluoride, only one broad signal can be observed downfield $0.3 \mathrm{ppm}$ (11.15 ppm) compared to the signal previously observed, including both $\mathrm{NH}$ and 



Figure 5. Fluorescence titration spectra of compounds 8 (left) and $\mathbf{9}$ (right) in DMSO upon addition of the fluoride ion ranges of 0.1-1.4 equiv. (a) and (b) on top, respectively and 1.4-10 equiv. (c) and (d) on bottom.

hydroxyl $\mathrm{OH}$. Finally, at 0.8 equiv., the broad signal shifts downfield another $0.2 \mathrm{ppm}$, unlike that observed in receptors containing the same chemical grouping, where the signal related to NHs completely disappears. ${ }^{20} \mathrm{~A}$ similar behavior was observed to compound $\mathbf{9}$. Although the literature shows a relation between the disappearing of hydrogen signals in the ${ }^{1} \mathrm{H}$ NMR titration with a full proton transfer from the chemosensor to the analyte, ${ }^{48}$ some authors also indicate the disappearing of signals from the chemosensor due to hydrogen bonding ${ }^{6,49}$ or both. ${ }^{20}$ There is no clear definition concerning this experiment and the proposed interaction mechanism. In this work, in a general way, it was observed that the thiourea hydrogens shift downfield and remain present during titration, which in our opinion corroborates the HB mechanism in this site of the molecule. Concerning the two additional acidic sites, the signal from the carboxylic hydrogen disappears at the first addition of fluoride, as expected due to the lower pKa value. Moreover, the signal from the phenolic hydrogen also remains almost unchanged, probably due to the strong IHB present in these compounds, located at $11.13 \mathrm{ppm}$ during titration, indicating that fluoride does not interact with the phenolic $\mathrm{OH}$ (see full spectra in the SI section). This interaction mechanism corroborates the evidence already observed in the UV-Vis and fluorescence emission complexation titrations. Based on the above investigation results, a possible binding mechanism between chemosensors 8-9 and $\mathrm{F}^{-}$was proposed in Scheme 3. 

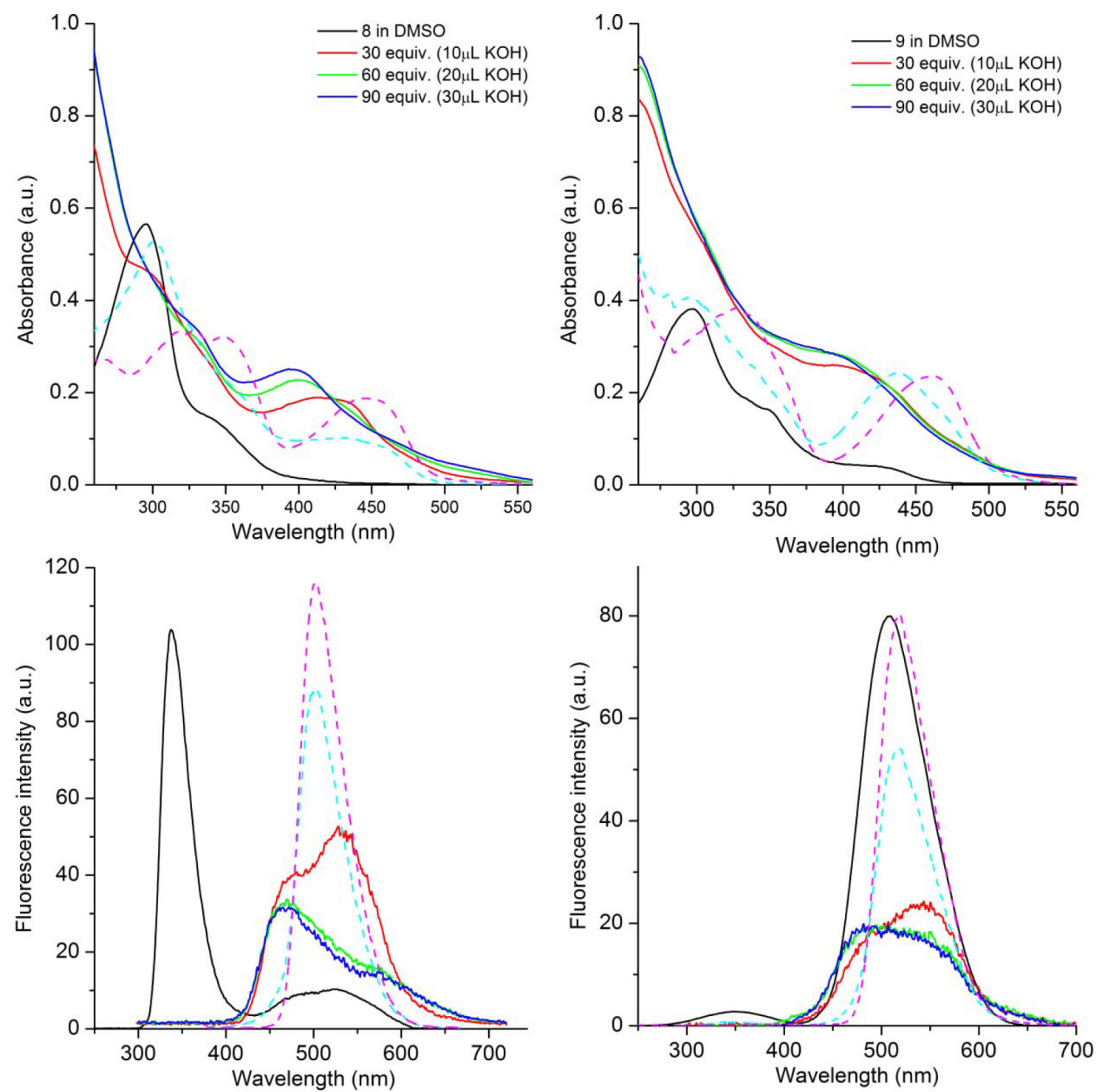

Figure 6. Absorption (top) and emission spectra (bottom) of compounds 8 (left) and $\mathbf{9}$ (right) in DMSO in presence of KOH (30-90 equiv.). The dash lines correspond to the chemosensors with similar amount of fluoride (cyan: 30 equiv. and magenta: 60 equiv.). The intensities of chemosensors in DMSO and in presence of fluoride are divided by 5 for better comparison.

\section{Conclusions}

In summary, here we have reported the synthesis and photophysical characterization of two thiourea derivatives 8-9, based on photoactive aminohydroxybenzazole dyes. These compounds were investigated as chemosensors for ions in solution. The compounds present absorption maxima located around $300 \mathrm{~nm}$ with molar absorptivity coefficient values ascribed to allowed ${ }^{1} \pi \pi^{*}$ electronic transitions. Both compounds present dual fluorescence emission due to the ESIPT process: an emission located in the UV-A region $\left(\Delta \lambda_{\text {ST }}\right.$ ca. $\left.3400 \mathrm{~cm}^{-1}\right)$, so-called normal emission, and a redshifted one located in the green region $\left(\Delta \lambda_{\mathrm{ST}}\right.$ ca. $\left.13000-14000 \mathrm{~cm}^{-1}\right)$, ascribed to the tautomeric emission. Concerning the complexation studies, compounds 8-9 signaled the presence of the fluoride ion in solution by naked-eye detection, probably due to hydrogen bonding between the chemosensor and $\mathrm{F}^{-}$, which increased charge transfer in these compounds. The results of UV-Vis titration indicate that $\mathbf{8}$ is more sensitive to the fluoride ion than $\mathbf{9}$, as upon the addition of small amounts of fluoride, a new absorption band can be observed located around $450 \mathrm{~nm}$, being related to the binding complex between compound $\mathbf{8}$ and fluoride. This interaction was also investigated by ${ }^{1} \mathrm{H}$ NMR titration. After the addition of different amounts of fluoride, the $\mathrm{NH}$ signals seem to lose resolution and collapse to a broad signal. The preliminary results indicate that these compounds can be used as chemosensors to identify anionic species in solution, in particular the fluoride 


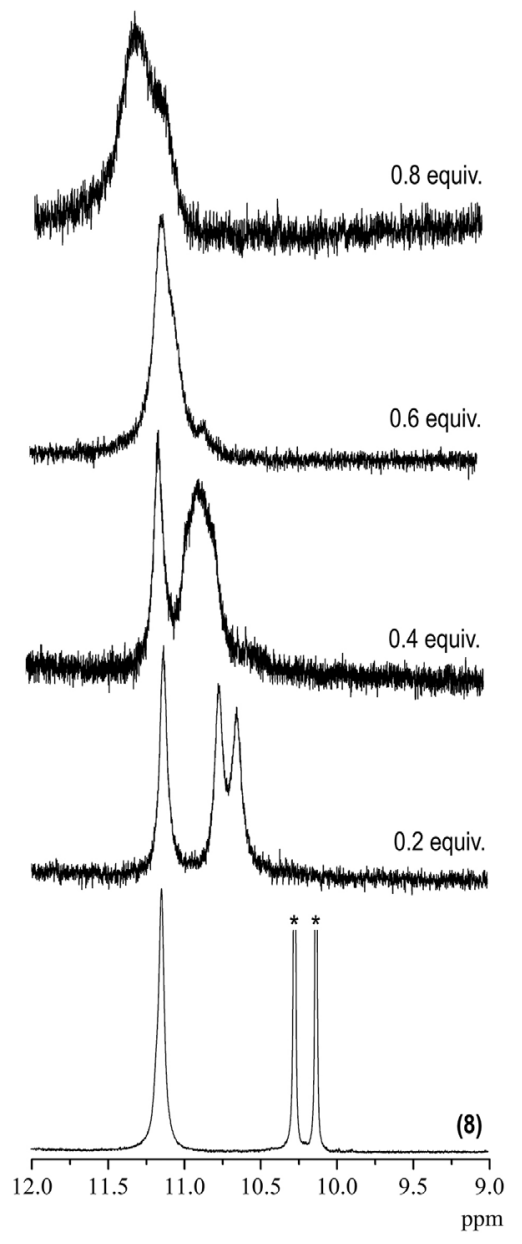

Figure 7. ${ }^{1} \mathrm{H}$ NMR titration of compound 8 (ca. $10^{-5} \mathrm{M}$ in DMSO- $d_{6}$ ) with TBAF in DMSO- $d_{6}\left(9.54 \times 10^{-3} \mathrm{M}\right)$ at room temperature using different amounts of the anion solution (0.2-0.8 equiv.).

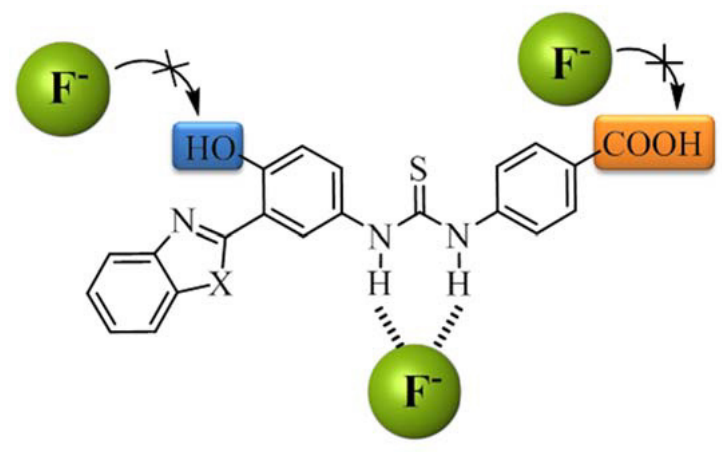

Scheme 3. The binding model between chemosensors 8-9 and fluoride, where $\mathrm{X}=\mathrm{O}$ or $\mathrm{S}$.

anion, through an HB interaction mechanism. With respect to previously published data, similar results were obtained for the identification of fluoride in solution in chemosensors containing the same signaling group, although in the studied compounds $\mathbf{8 - 9}$, the presence of this anion in solution not only allows ESIPT emission but tailors it in both compounds.

\section{Supplementary Information}

Original ${ }^{1} \mathrm{H}$ NMR, ${ }^{13} \mathrm{C}$ NMR and FTIR spectra of synthesized compounds, as well as additional photophysical data for the complexation studies are available free of charge at http://jbcs.sbq.org.br as PDF file.

\section{Acknowledgments}

This research was financially supported by $\mathrm{CNPq}$, CAPES and Instituto Nacional de Inovação em Diagnósticos para a Saúde Pública (INDI-Saúde). Special thanks to MSc Alexsandro Dallegrave for the HRMS results.

\section{References}

1. Martínez-Máñez, R.; Sancenón, F.; Chem. Rev. 2003, 103, 4419.

2. Duke, R. M.; Veale, E. B.; Pfeffer, F. M.; Kruger, P. E.; Gunnlaugsson, T.; Chem. Soc. Rev. 2010, 39, 3936.

3. Kim, S. Y.; Hong, J. I.; Org. Lett. 2007, 9, 3109.

4. Xu, Z.; Kim, S.; Kim, S.; Kim, H. N.; Han, S. J.; Lee, C.; Kim, J. S.; Qian, X.; Yoon, J.; Tetrahedron Lett. 2007, 48, 9151.

5. Basu, A.; Dey, S. K.; Das, G.; RSC Adv. 2013, 3, 6596.

6. Bao, X.; Yu, J.; Zhou, Y.; Sens. Actuators, B 2009, 140, 467.

7. Duke, M. R.; Gunnlaugsson, T.; Tetrahedron Lett. 2007, 48, 8043.

8. Jun, E. J.; Swamy, K. M. K.; Bang, H.; Kim, S. J.; Yoon, J.; Tetrahedron Lett. 2006, 47, 3103.

9. Camargo, J. A.; Chemosphere 2003, 50, 251.

10. Barbier, O.; Arreola-Mendoza, L.; Del Razo, L. M.; Chem.-Biol. Interact. 2010, 188, 319.

11. Everett, E. T.; J. Dent. Res. 2011, 90, 552.

12. Faibish, D.; Ott, S. M.; Boskey, A. L.; Clin. Orthop. Relat. Res. 2006, 443, 28.

13. Ayoob, S.; Gupta, A. K.; Crit. Rev. Environ. Sci. Technol. 2006, $36,433$.

14. Gunnlaugsson, T.; Kruger, P. E.; Jensen, P. J.; Tierney, J; Ali, H. D. P.; Hussey, G. M.; J. Org. Chem. 2005, 70, 10875.

15. Gunnlaugsson, T.; Glynn, M.; Tocci, G. M.; Kruger, P. E.; Pfeffer, F. M.; Coord. Chem. Rev. 2006, 250, 3094.

16. Bondy, C. R.; Loeb, S. J.; Coord. Chem. Rev. 2003, $240,77$.

17. Gale, P. A.; Coord. Chem. Rev. 2001, 213, 79.

18. Jose, D. A.; Kumar, D. K.; Ganguly, B.; Das, A.; Org. Lett. 2004, 6, 3445.

19. Suksai, C.; Tuntulani, T.; Chem. Soc. Rev. 2003, 32, 192.

20. Kumar, V.; Rana, H.; Kaushik, M. P.; Analyst 2011, 136, 1873.

21. Shao, J.; Lin, H.; Yu, M.; Cai, Z.; Lin, H.; Talanta 2008, 75, 551.

22. Brewer, W. E.; Martinez, M. L.; Chou, P. T.; J. Phys. Chem. 1990, 94, 1915. 
23. Santos, F. S.; Ramasamy, E.; Ramamurthy, V.; Rodembusch, F. S.; J. Photochem. Photobiol., A 2016, 317, 175.

24. Kwon, J. E.; Park, S. Y.; Adv. Mater. 2011, 23, 3615.

25. Zhao, J. Z.; Ji, S. M.; Chen, Y. H.; Guo, H. M.; Yang, P.; Phys. Chem. Chem. Phys. 2012, 14, 8803.

26. Lochbrunner, S.; Wurzer, A. J.; Riedle, E.; J. Phys. Chem. A 2003, 107, 10580.

27. Abou-Zied, O. K.; Phys. Chem. Chem. Phys. 2012, 14, 2832.

28. Paul, B. K.; Guchhait, N.; J. Lumin. 2014, 153, 430.

29. Simkovitch, R.; Shomer, S.; Gepshtein, R.; Shabat, D.; Huppert, D.; J. Phys. Chem. A 2014, 118, 1832.

30. Pal, S. K.; Zewail, A. H.; Chem. Rev. 2004, 104, 2099.

31. Rodembusch, F. S.; Campo, L. F.; Leusin, F. P.; Stefani, V.; J. Lumin. 2007, 126, 728.

32. Santos, F. S.; Medeiros, N. G.; Affeldt, R. F.; Duarte, R. D.; Moura, S.; Rodembusch, F. S.; New J. Chem. 2016, 40, 2785.

33. Daengngern, R.; Kungwan, N.; Chem. Phys. Lett. 2014, 609, 147.

34. Padalkar, V. S.; Ramasami, P.; Sekar, N.; J. Lumin. 2014, 146, 527.

35. Armarego, W. L. F.; Purification of Laboratory Chemicals, $5^{\text {th }}$ ed.; Elsevier Academic Press: Cornwall, UK, 2003.

36. Bordwell, F. G.; Boutan, P. J.; J. Am. Chem. Soc. 1956, 78, 854.

37. Santos, F. S.; Ramasamy, E.; Ramamurthy, V.; Rodembusch, F. S.; J. Mater. Chem. C 2016, 4, 2820.

38. Coelho, F. L.; Rodembusch, F. S.; Campo, L. F.; Dyes Pigm. 2014, 110, 134.
39. Ireland, T. A.; Wyatt, P. A. H.; Adv. Phys. Org. Chem. 1976, 12, 131

40. Strickler, S. J.; Berg, R. A.; J. Phys. Chem. 1962, 37, 814.

41. Turro, N. J.; Scaiano, J. C.; Ramamurthy, V.; Principles of Molecular Photochemistry: An Introduction, $1^{\text {st }}$ ed.; University Science Books: Sausalito, USA, 2008.

42. Sargeant, E. P.; Dempsey, B.; Ionisation Constants of Organic Acids in Aqueous Solution, IUPAC No. 23; Pergamon Press: New York, USA, 1979.

43. Gomez, D. E.; Fabbrizzi, L.; Licchelli, M.; Monzani, E.; Org. Biomol. Chem. 2005, 3, 1495.

44. Mishra, A.; Chaterjee, S.; Krishnamoorthy, G.; J. Photochem. Photobiol., A 2013, 260, 50.

45. Santos, F. S.; Ramasamy, E.; Ramamurthy, V.; Rodembusch, F. S.; Photochem. Photobiol. Sci. 2014, 13, 992.

46. Abou-Zied, O. K.; Chem. Phys. 2007, 337, 1.

47. Krishnamurthy, M.; Dogra, S. K.; J. Photochem. 1986, 32, 235.

48. Liu, S.; Zhang, L.; Zhou, P.; Zan, W.; Yao, X.; Yang, J.; Yang, Y.; RSC Adv. 2015, 5, 19983.

49. Kumar, V.; Kaushik, M. P.; Srivastavaa, A. K.; Pratap, A.; Thiruvenkatam, V.; Row, T. N. G.; Anal. Chim. Acta 2010, 663, 77.

Submitted: April 3, 2017

Published: May 31, 2017

FAPERGS/CAPES has sponsored the publication of this article. 